\title{
Microbiota bacteriana e citologia da região traqueobrônquica de bezerros no período neonatal ${ }^{1}$
}

\author{
Fernando J. Benesi2*, Heloisa G. Bertagnon ${ }^{3}$, Lucia Wachholz ${ }^{3}$, Marta L.R. Leal ${ }^{3}$, \\ Wilson R. Fernandes ${ }^{2}$, Nilson R. Benites ${ }^{4}$ e Pricila A. Melville ${ }^{5}$
}

\begin{abstract}
Benesi F.J., Bertagnon H.G., Wachholz L., Leal M.L.R., Fernandes W.R., Benites N.R. \& Melville P.A. 2013. [Bacterial pathogens and cytology or tracheobronchial region in calves during neonatal period.] Microbiota bacteriana e citologia da região traqueobrônquica de bezerros no período neonatal. Pesquisa Veterinária Brasileira 33(6):700-704. Departamento de Clínica Médica, Faculdade de Medicina Veterinária e Zootecnia, Universidade de São Paulo, Av. Prof. Dr. Orlando Marques de Paiva 87, São Paulo, SP 05508-270, Brazil. E-mail: febencli@usp.br

Bronchopneumonia is important for world livestock production and one of the major causes of calf mortality during the first months of life. The preventive and therapeutic measures adopted for the disease in calves in Brazil are usually based on the results of international studies; however there is not enough known which bacteria are implicated. In the first month of life calves show immaturity of their immune system, what has been little studied in regard to pneumonia. The present investigation sought to study neonate bronchopneumonia in calves, to identify which bacteria are present in the respiratory tract of healthy and, with naturally acquired pneumonia calves, to analyze the pulmonary cytological response against pathogens. For this purpose, samples of the respiratory tract were collected by tracheocenthesis. It was noted that the microflora of the tracheobronchial region of healthy and diseased calves was the same, but they were different from the one reported by international papers. The flora was constituted mainly by Staphylococcus sp., Bacillus sp., Streptococcus sp., Pseudomonas aeruginosa and enterobacteriae, allowing to infer that the prophylactic and therapeutic measures adopted internationally may not be as effective for the Brazilian condition. It was also found that newborn calves have an approximate ratio of 1:1 of macrophages and neutrophils in the tracheobronchial region when they were healthy, reaching a ratio of approximately 1:3 of macrophages and neutrophils when they were with bronchopneumonia. Probably, these profiles are characteristic of the age, a period when exists immaturity of the immune system and influenced by management factors which lead to greater inhalation of bacterial agents.
\end{abstract}

INDEX TERMS: Alveolar macrophage, cattle, Mannheimia sp., pneumonia, tracheocenthesis.

\footnotetext{
${ }^{1}$ Recebido em 2 de outubro de 2012.

Aceito para publicação em 14 de fevereiro de 2013.

${ }^{2}$ Departamento de Clínica Médica, Faculdade de Medicina Veterinária e Zootecnia (FMVZ), Universidade de São Paulo (USP), Av. Prof. Dr. Orlando Marques de Paiva 87, São Paulo, SP 05508-270, Brasil. *Autor para correspondência: febencli@usp.br

${ }^{3}$ Pós-Graduandos do Programa de Clínica Veterinária, Departamento de Clínica Médica, FMVZ-USP, São Paulo, SP.

${ }^{4}$ Departamento de Medicina Veterinária Preventiva e Saúde Animal, FMVZ-USP, São Paulo, SP.

${ }^{5}$ Técnica do Laboratório de Doenças Infecciosas do Departamento de Medicina Veterinária Preventiva e Saúde Animal, FMVZ-USP, São Paulo, SP.
}

RESUMO.- As broncopneumonias são afecções importantes na pecuária mundial, representando uma das principais causas de mortalidade de bezerros nos primeiros meses de vida. As medidas preventivas e terapêuticas adotadas geralmente são baseadas em resultados de estudos internacionais, não se conhecendo as bactérias implicadas nos quadros pneumônicos em animais criados no Brasil. Aliado a isso, no primeiro mês de vida, os bezerros demonstram imaturidade do sistema imune, o que tem sido pouco estudado em quadros pneumônicos. Desta maneira, objetivou-se estudar as broncopneumonias em bezerros neonatos, 
identificando bactérias do trato respiratório posterior de bezerros sadios e com pneumonias naturalmente adquiridas, bem como analisar citologicamente a resposta pulmonar frente a estes patógenos. Para isso amostras de lavado do trato respiratório foram colhidas por traqueocentese durante o primeiro mês de vida dos animais. Verificou-se que não houve diferença na microbiota traqueobrônquica de bezerros sadios em relação aos doentes, discordando dos relatos da literatura internacional, sendo constituída principalmente por: Staphylococcus sp., Bacillus sp., Streptococcus sp., Pseudomonas aeruginosa e enterobactérias, permitindo inferir que as medidas profiláticas e terapêuticas adotadas internacionalmente possam não ser tão efetivas para as criações brasileiras. Observou-se também que bezerros neonatos têm uma proporção aproximada de 1:1 de macrófagos e neutrófilos na região traqueobrônquica quando saudáveis, atingindo uma relação aproximada de 1:3 durante os quadros de broncopneumonias, sendo estes perfis provavelmente característicos da idade, período conhecido pela imaturidade do sistema imune e agravado por fatores de manejo que favoreçam uma maior inalação de agentes bacterianos.

TERMO DE INDEXAÇÃO: Bovinos, macrófago alveolar, Mannheimia sp., pneumonia, traqueocentese.

\section{INTRODUÇÃO}

0 período neonatal dos bezerros, representado pelo primeiro mês de vida, tem como ponto central o seu direcionamento para a adaptação do recém-nascido à vida extrauterina. Caracteriza-se por apresentar as maiores taxas de mortalidade de bezerros, sendo o sistema respiratório freqüentemente acometido por enfermidades, ocasionando prejuízo direto da sua função, com evolução para a morte ou desenvolvimento retardado nos animais sobreviventes (Benesi 1993).

O exame físico, em particular a auscultação pulmonar, nem sempre é elucidativa de uma doença respiratória, e o diagnóstico definitivo requer exames complementares mais específicos como radiografia, broncoscopia ou análises citológicas e microbiológicas do trato respiratório (Gonçalves et al. 2004; Poulsen \& McGuirk 2009). Alguns destes exames requerem equipamentos onerosos, impedindo sua execução corriqueira, induzindo a necessidade do desenvolvimento de técnicas mais baratas que forneçam informações precisas para o reconhecimento da higidez do trato respiratório de bovinos. Assim pesquisas têm sido realizadas visando conhecer a citologia e microbiota bacteriana do trato respiratório de animais sadios (Pringle et al. 1988, Barros et al. 1994, Bertagnon et al. 2011, Gonçalves et al. 2011, Benesi et al. 2012).

Destes trabalhos destaca-se que mesmo havendo variações fisiológicas decorrentes da raça, sexo e idade, ou ainda decorrentes do manejo dos animais, bem como da técnica adotada para a colheita, o trato respiratório de bovinos sadios com mais de um mês de idade apresenta citologia com uma predominância de macrófagos alveolares, seguida por neutrófilos e pequenas proporções de células epiteliais, eosinófilos e linfócitos (Pringle et al. 1988, Barros et al. 1994,
Griffin et al. 2010, Gonçalves et al. 2004). Em bezerros com idade inferior a um mês, Benesi et al. (2012) encontraram de forma diversa um padrão citológico com predomínio neutrofilico, provavelmente devido à técnica de colheita traqueobrônquica por punção traqueal, ser considerada invasiva quando utilizada sequencialmente em intervalos semanais.

Na avaliação microbiológica, uma importante ferramenta diagnóstica, os agentes microbianos mais envolvidos nos quadros de pneumonias são organismos que compõe a microbiota do trato respiratório anterior de ruminantes saudáveis, mantendo uma relação comensal com o hospedeiro, até que condições de estresse ou coinfecções resultem em multiplicação exagerada daqueles, determinando o aparecimento de doenças (Griffin et al. 2010). Apesar das bactérias Pausterella multocida, Mannheimia haemolytica, Histophilus somnus, Arcanobacterium pyogenes, Mycoplasma spp. associadas a vírus serem mundialmente reconhecidas como as principais causadoras de pneumonias de bezerros (Vogel et al. 2001, Angen et al. 2009, Griffin et al. 2010), não há isolamento das mesmas em trato respiratório de animais criados em determinadas regiões do planeta. Não isolou-se por exemplo, Mannheimia haemolytica. , Histophilus somnus, Arcanobacterium pyogenes, Mycoplasma spp do trato respiratório de bezerros sadios e com broncopneumonia criados na Finlândia (Autio et al. 2007). No Brasil, a literatura existente abordando esta temática esta restrita às décadas de 80 e 90 , na qual nenhuma das bactérias retromencionadas foram isoladas, sendo os microorganismos mais encontrados as enterobactérias: Enterobacter sp., Proteus mirabilis, Escherichia coli, Klebsiella sp., Enterococcus sp., seguidas por outros agentes como Pseudomonas aeruginosa, Propionibacterium sp., Staphylococcus epidermidis, Alcaligenes sp., e Streptococcus $\beta$-hemolítico (Gonçalves 1987, Barros et al. 1994).

O impacto da mannheimiose bovina, causada pela $M$. haemolytica, é bem conhecido na América Norte e Europa, porém pouco se sabe sobre sua incidência na América Latina (Jaramillo-Arango et al. 2009). Apenas Cardoso et al. (2002) citam o isolamento de Mycoplasma spp. e Mannheimia haemolytica em um surto de broncopneumonia em bezerros, em amostras obtidas durante necropsia, em São Paulo, necessitando-se portanto melhor conhecer a microbiota bacteriana normal e patogênica dos bezerros criados sob manejo e condições mesológicas do Brasil.

Além do que, são poucas as pesquisas nacionais que estudaram a citologia (Gonçalves et al. 2004, 2011, Bertagnon et al. 2011, Benesi et al. 2012) e microbiologia (Gonçalves 1987, Barros et al. 1994) do trato respiratório posterior de bezerros. Assim sendo, neste estudo propôs-se identificar a microbiota bacteriana e a citologia característica da região traqueobrônquica de bezerros neonatos sadios e com broncopneumonias naturalmente adquiridas, com o intuito de fornecer subsídios para estabelecer medidas profiláticas e terapêuticas mais efetivas aos bezerros criados em condições brasileiras.

\section{MATERIAL E MÉTODOS}

A investigação foi realizada em bezerros machos holandeses durante o primeiro mês de vida, que mamaram de forma adequada 
colostro, comprovado por meio de dosagem de proteína sérica superior a 5,0g/dL e Imunoglobulina G sérica acima de $1500 \mathrm{mg} /$ dL. Os animais foram alojados em gaiolas individuais no setor experimental da clínica de bovinos e pequenos ruminantes da FMVZ- USP dos primeiros dias pós-nascimento até completarem 30 dias de vida, sendo alimentados com dois litros de sucedâneo de leite duas vezes por dia, água, ração peletizada, capim verde e feno ad libitum, e avaliados diariamente para verificar presença de pneumonia.

Durante o período experimental, 22 animais manifestaram broncopneumonia e 49 se mantiveram clinicamente saudáveis. A higidez dos bezerros foi verificada através de ausência de alterações nos exames físico e laboratoriais (hemograma, dosagem de fibrinogênio, hemogasometria arterial e bioquímica sérica para avaliar funções hepática e renal). A doença clinica foi considerada presente quando os bezerros apresentaram pelo menos duas das manifestações a seguir listadas: temperatura retal acima de 39,5C; secreção nasal mucopurulenta ou purulenta; tosse; reflexo de tosse positivo; estertoração e/ou crepitação na auscultação pulmonar e aumento da freqüência respiratória acima de 40 $\mathrm{MR} / \mathrm{min}$.

Para as avaliações citológicas e microbiológicas do lavado do trato respiratório, foi realizada coleta do lavado traqueobrônquico. Após previa tricotomia e assepsia, puncionou-se a traquéia na região do segundo anel traqueal com uma agulha de $14 \mathrm{G}$ x $5 \mathrm{~cm}$, e pela agulha, inseriu-se um cateter de polietileno ${ }^{6}$ até a bifurcação traqueal. 0 lavado foi realizado após a instilação de quatro alíquotas de $10 \mathrm{ml}$ cada, de solução fisiológica $0,9 \%$ a temperatura ambiente e o conteúdo foi recuperado por aspiração imediata com seringa plástica de $60 \mathrm{~mL}$.

Uma alíquota de lavado foi submetida a exames microbiológicos, pelos cultivos em caldo BHI, em ágar sangue de carneiro (5\%) e ágar MacConkey para isolamento bacteriano e em ágar Sabouraud-dextrose com cloranfenicol $(100 \mathrm{mg} / \mathrm{L})$ para o isolamento e identificação de fungos filamentosos e leveduras. As colônias bacterianas isoladas foram submetidas a exames macroscópicos e microscópicos, procedendo-se à identificação por testes bioquímicos de acordo com Murray et al. (1999).

Posteriormente uma alíquota de $200 \mu \mathrm{L}$ do lavado foi citocentrifugada a 28 g, por 6 minutos. As lâminas de microscopia contendo as células foram fixadas com álcool metílico e coradas com o método de Rosenfeld conforme recomendações descritas por Fernandes et al. (2000). A leitura das lâminas foi realizada em microscopia óptica de imersão, qualificando-se 400 células por lâmina de acordo com suas características morfológicas e tintoriais em células epiteliais, macrófagos alveolares, neutrófilos, linfócitos e eosinófilos.

A análise estatística foi realizada utilizando o programa estatístico computadorizado Minitab (1998). Para cada grupo, foram calculadas as medianas e primeiros e terceiros quartis, utilizando-se testes não paramétricos de Mann- Whitney, sendo consideradas diferenças significativas quando $\mathrm{P}$ apresentou valores iguais ou inferiores a 0,05 (Sampaio 1998).

\section{RESULTADOS E DISCUSSÃO}

A porcentagem das bactérias isoladas e a analise citológica, expressa em medianas da região traqueobrônquica de bezerros sadios e pneumônicos estão apresentados respectivamente nos Quadros 1 e 2.

Apesar de a literatura citar Pausterella multocida, M. haemolytica, Histophilus somnus, Arcanobacterium pyogenes como os agentes mais comuns isolados do trato respirató-

\footnotetext{
${ }^{6}$ Intracathy $\mathrm{BD}^{\circledR}$.
}

Quadro 1. Isolamento bacteriano de lavado traqueobrônquico obtido por traqueocentese de bezerros sadios e com broncopneumonia. São Paulo, 2012

\begin{tabular}{|c|c|c|}
\hline \multirow[t]{2}{*}{ Bactérias isoladas } & \multicolumn{2}{|c|}{ Bezerros } \\
\hline & $\begin{array}{l}\text { Clinicamente saudáveis } \\
\text { (\% das medianas) } \\
n=49\end{array}$ & $\begin{array}{c}\text { Broncopneumonia } \\
\text { ( } \% \text { das medianas) } \\
n=22\end{array}$ \\
\hline Staphylococcus sp. & $36,73^{a}$ & $31,82^{a}$ \\
\hline Bacillus sp. & $32,65^{\mathrm{a}}$ & $31,82^{\mathrm{a}}$ \\
\hline Streptococcus sp. & $22,45^{\mathrm{a}}$ & $31,82^{\underline{a}}$ \\
\hline Pseudomonas aeruginosa & $2,04^{\underline{a}}$ & $0 \stackrel{\mathrm{a}}{ }$ \\
\hline Klebsiella sp. & $14,28^{\mathrm{a}}$ & $31,82^{\mathrm{a}}$ \\
\hline Proteus sp. & $0 \mathrm{a}$ & $9,09 \underline{a}$ \\
\hline Escherichia coli & $16,33^{a}$ & $4,55^{\mathrm{a}}$ \\
\hline colônias puras & $42,86^{\mathrm{a}}$ & $63,64^{\mathrm{b}}$ \\
\hline colônias mistas & $38,78^{a}$ & $36,36^{\mathrm{a}}$ \\
\hline $\mathrm{N}$ amostras negativas & $18,37^{\text {a }}$ & $0^{\mathrm{b}}$ \\
\hline
\end{tabular}

Medianas com letras não coincidentes em mesma linha indicam diferença estatística entre os grupos $(\mathrm{p} \leq 0,05)$.

Quadro 2. Percentuais das medianas (primeiro e terceiro quartis) de células do lavado traqueobrônquico de bezerros sadios e com broncopneumonia. São Paulo, 2012

\begin{tabular}{|c|c|}
\hline Células da região & Bezerros \\
\hline traqueobrônquica & $\begin{array}{l}\text { Clinicamente saudáveis } \quad \text { Broncopneumonia } \\
\mathrm{n}=48 \text { Mediana (\%) (pri- } \\
\text { meiro e terceiro quartil) }\end{array}$ \\
\hline
\end{tabular}

Macrófagos alveolares $42,87^{\text {a }}(43,58 ; 57,42) \quad 11,37^{\text {b }}(11,82 ; 33,04)$

Células epiteliais $\quad 0,0^{\mathrm{a}}(8,32 ; 24,61) \quad 0,0^{\mathrm{a}}(0,0 ; 11,36)$

Neutrófilos $\quad 35,75^{\mathrm{a}}(28,76 ; 43,57) \quad 84,37^{\mathrm{b}}(56,15 ; 83,39)$

Linfócitos $\quad 1,75^{\mathrm{a}}(2,50 ; 5,77) \quad 1,50$ a $(0,8 ; 4,60)$

Eosinófilos $\quad 0,02^{\mathrm{a}}(0 ; 4,0) \quad 0,01^{\underline{a}}(0 ; 3,0)$

Medianas com letras não coincidentes em mesma linha indicam diferença estatística entre os grupos $(\mathrm{p} \leq 0,05)$.

rio posterior de bezerros sadios e com broncopneumonia (Vogel et al. 2001, Angen et al. 2009, Griffin et al. 2010), estes agentes não foram encontrados na presente pesquisa.

As bactérias mais frequentemente encontradas foram semelhantes nos animais sadios e nos doentes, o que poderia causar dúvidas sobre a correta interpretação da hígidez dos bezerros, uma vez que apenas o exame físico nem sempre é suficiente para caracterizar uma doença pulmonar (Gonçalves et al. 2004, Poulsen \& McGuirk 2009). Por isso os exames laboratoriais como hemograma, em especial a dosagem de fibrinogênio, foram fundamentais para descartar erros de interpretações clínicas, pois segundo Taylor (2000) constituem os indicadores mais sensíveis de inflamação aguda ou crônica.

Os agentes isolados da região traqueobrônquica são relacionados ao meio ambiente, sendo frequentemente inalados e encontrados compondo a microbiota do trato respiratório anterior de ruminantes saudáveis (Vogel et al. 2001, Griffin et al. 2010). Os grupos experimentais foram compostos por animais de diversas origens e abrigados juntos no setor de experimentação da clínica de bovinos e pequenos ruminantes, em condições diversas daquelas originais de sua criação, favorecendo diversidade e alta taxa de bactérias expiradas no ambiente. Além disso, animais jovens apresentam depuração mucociliar baixa, deixando-os mais vulneráveis a agentes bacterianos inalados (Diesel et al. 1991) 
Encontrou-se uma grande proporção de enterobactérias nas amostras de animais sadios e naquelas dos doentes, o que difere do descrito pela literatura internacional, mas não da nacional (Gonçalves 1987, Barros et al. 1994). Apesar dos bezerros estarem instalados em gaiolas individuais, a sua proximidade permitia que um animal lambesse a região da cabeça dos outros, favorecendo uma possível contaminação oronasal (Poulsen \& McGuirk 2009). Além disso, nesta faixa etária, os animais frequentemente apresentavam quadros diarréicos, observando-se crostas de material fecal nos mesmos, o que possibilita maior contato com as enterobactérias. Acredita-se que estas condições de manejo, que permitam contato entre focinhos, favoreçam uma colonização do trato respiratório diferente daquela relatada pela literatura internacional.

Fatores relacionados com o manejo: como estresse, mudanças drásticas de temperatura, superlotação, transporte, confinamento de animais de diferentes idades, desmame e falha na transferência de imunidade passiva favorecem surtos de mannheimiose (Jaramillo-Arango et al. 2009), no entanto os animais do presente estudo, submetidos a algumas das condições acima citada, não apresentaram cultura positiva de Mannheimia haemolytica. Além disso, os surtos de mannhemiose normalmente ocorrem em países de clima temperado em épocas de inverno e outono, sugerindo-se que talvez o clima tropical do Brasil não favoreça o aparecimento da doença em proporções significativas como relatadas na América do Norte e Europa (Lo, 2001; Vogel et al. 2001, Griffin et al. 2010).

As pesquisas referentes a citologia da região traqueobrônquica em bezerros sadios ressaltaram um predomínio de macrófagos sobre neutrófilos (Gonçalves et al. 2004, Griffin et al. 2010), de forma diversa da presente pesquisa, que encontrou uma proporção de quase 1:1 (entre macrófagos e neutrófilos) nos bezerros sadios. A técnica de colheita, condições de manejo (Pringle et al. 1988, Barros et al. 1994, Bertagnon et al. 2007), bem como a idade dos bezerros (Gonçalves et al. 2011, Benesi et al. 2012), influenciam diretamente a população citológica. Com a finalidade de excluir interferências destas variáveis, comparou-se o grupo dos animais doentes com os sadios e notou-se um grande influxo de neutrófilos nos dois grupos, com maiores magnitudes nos doentes (proporção de 1:3). Tal fato poderia ser explicado pela alta colonização do trato respiratório por agentes bacterianos inalados, aliado à imaturidade do sistema imune (Diesel et al. 1991, Benesi et al. 2012). Durante o primeiro trimestre de vida de bezerros, há imaturidade da atividade fagocítica e do metabolismo oxidativo dos fagócitos respiratórios frente a estímulos (Batista et al. 2012). Além disso, parece haver uma redução contínua da imunoglobulina IgA na região traqueobrônquica durante o primeiro mês de vida, tornando a região mais dependente de resposta celular (Bertagnon et al. 2007).

A magnitude de aumento neutrofílico durante a infecção pulmonar pode não ser representativa da gravidade da broncopneumonia, assim como concluído por Gonçalves et al. (2011) em seu estudo para bovinos neonatos, já que devido a imaturidade imune, neonatos montaram uma resposta inflamatória menos severa, com pouca sintoma- tologia e grande influxo celular já que a eficiência celular é menor. Os animais mais velhos recrutam menor número de neutrófilos, que são mais eficientes na eliminação dos patógenos, porém mais danosa ao tecido hospedeiro (Grell et al. 2005, Batista et al. 2012), o que permite inferir que esta faixa etária arquiteta de uma forma particular, a magnitude de resposta a patógenos pulmonares.

\section{CONCLUSÕES}

Conclui-se que a microbiota traqueobrônquica de bezerros neonatos sadios e com broncopneumonias é similar e por tal razão difere do que é relatado pela literatura internacional, inferindo-se que as medidas profiláticas e terapêuticas recomendadas nesses trabalhos não devam ser adotadas tacitamente nas criações brasileiras sem uma análise crítica prévia.

De igual maneira, a população citológica da região traqueobrônquica destes bezerros sadios foi diferente da relatada pela literatura consultada e parece ser característica da idade, e atribuída a fatores de manejo e imaturidade do sistema imune.

Agradecimentos.- A agência financiadora FAPESP (Auxílio Pesquisa no. 2000/06783-7).

\section{REFERÊNCIAS}

Angen O., Thomsen J., Larsen L.E., Larsen J., Kokotovic B., Heegaard P.M.H. \& Enemark J.M.D. 2009. Respiratory disease in calves: Microbiological investigations on trans-tracheally aspirated bronchoalveolar fluid and acute phase protein response. Vet. Microbiol. 137:165-171.

Autio T., Pohjanvirta T., Holopainen R., Rikula U., Pentikainen J., Huovilainen A., Rusanen H., Soveri T., Sihvonen L. \& Pelkonen S. 2007. Etiology of respiratory disease in non-vaccinated, non-medicated calves in rearing herds. Vet. Microbiol. 119:256-265.

Barros M.S.R.M., Castro R.S., Tabosa J.H.C., Brito M.F. \& Amaral B. 1994. Colheita do fluído brônquico-alveolar de bezerros através da traqueocêntese transcutânea. Arq. Bras. Med. Vet. Zootec. 46:41-49.

Batista C.F., Blagitz M.G., Santos B.P., Bertagnon H.G., Parra A.C., Vianna R.S., de Lucca G.G., Lima D.M., Santos D.S. \& Della Libera A.M. 2012. Maturation of mononuclear phagocytes in the lungs of young calves-In vitro study. J. Dairy Sci. 95(10):5909-5915.

Benesi F.J. 1993. Síndrome asfixia neonatal dos bezerros: importância e avaliação crítica. Arq. Esc. Med. Vet. UFBA 16:38-48.

Benesi F.J., Wachholz L., Bertagnon H.G., Leal M.L.R., Mori E. \& Fernandes W.R. 2012. Citologia dos lavados traqueobrônquico (LTB) e broncoalveolar (LBA) de bezerros holandeses sadios durante o primeiro mês de vida. Pesq. Vet. Bras. 32(3):267-270.

Bertagnon H.G., Silva P.E.G., Wachholz L., Leal M.L.R., Fernandes W.R. \& Benesi F.J. 2007. Imunoglobulinas no trato respiratório de bezerros sadios durante o primeiro mês de vida. Pesq. Vet. Bras. 27(12):487-490.

Bertagnon H.G., Esper G.V.Z., Emanuelli M.P. \& Pellegrine L.G. 2011. Influência meteorológica no leucograma e na população citológica do trato respiratório de bezerros. Pesq. Vet. Bras. 31(3):244-246.

Cardoso M.V., Sforsin A.J., Scarcelli E., Teixeira S.R., Miyashiro S., Campos F.R. \& Genovez M.E. 2002. Importância do diagnóstico diferencial em um surto de pneumonia enzoótica bovina. Arqs Inst. Biológico, São Paulo, 69(3):111-113.

Diesel D.A., Jack L.L. \& Tucker A. 1991. Pulmonary particle deposition and airway mucociliary clearence in cold-exposed calves. Am. J. Vet. Res. 52:1665-1671.

Fernandes W.R., Mori E. \& Sanches A. 2000. Avaliação citológica de lavados traqueobrônquico e broncoalveolar em cavalos clinicamente sa- 
dios pelo método de coloração de Rosenfeld. Arq. Bras. Med. Vet. Zootec. 52(6):604-609.

Grell S.N., Kirsten Tjornehoj U.R., Larsen L.E. \& Heegaard M.H. 2005. Marked induction of IL-6, haptoglobin and IFNg following experimental BRSV infection in young calves. Vet. Immunol. Immunopathol. 103:235245.

Griffin D., Chengappa M.M., Kuszak J. \& Scott McVey D. 2010. Bacterial pathogens of the bovine respiratory disease complex. Vet. Clin. North Am., Food. Anim. Pract. 26:381-394.

Gonçalves R.C. 1987. Estudo da flora traqueobrônquica em bezerros clinicamente sadios e portadores de pneumonia, na região de Botucatu, SP. Dissertação de Mestrado, Faculdade de Medicina Veterinária e Zootecnia, Universidade Estadual Paulista, Botucatu, SP. 44p.

Gonçalves R.C., Mattos M.C.F.I., Kuchembuck M.R.G., Lopes R.S. \& Borges A.S. 2004. Lavagem traqueobrônquica por sondagem nasotraqueal em bezerros Arq. Bras. Med. Vet. Zootec. 56(3):307-311.

Gonçalves R.C., Rocha A.E.A., Silva A.A., Takahira R.K. \& Chiacchio S.B. 2011. Influência da suplementação de vitamina $E$ na profilaxia e tratamento da broncopneumonia moderada e grave em bezerros Pesq. Vet. Bras. 31(2):127-135.

Jaramillo-Arango C.J., Tavera F.J.T. \& Suárez-Güemes F. 2009. Mannheimiosis bovina: etiología, prevención y control [Bovine mannheimiosis: etiology, prevention and control.]. Vet. Méx. 40(3):293-314.
Minitab 1998. The Student Edition of MINITAB Statistical software adapted for education - 12.1 Release, User's Manual. Addison-Wesley, New York. 624p.

Murray P.R., Baron E.J., Pfaller M., Tenover F.C. \& Yolken R.H. 1999. Manual of Clinical Microbiology. $7^{\text {th }}$ ed. American Society for Microbiology, Washington, DC. 1773p.

Lo R.Y. 2001. Genetic analysis of virulence factors of Mannheimia (Pasteurella) haemolytica A1. Vet. Microbiol. 83:23-35.

Pringle J.K., Viel L., Shewen P.E., Willoughby R.A., Martin S.W. \& Valli V.E. 1988. Bronchoalveolar lavage of cranial and caudal lung regions in selected normal calves: Cellular, microbiological, immunoglobulin, serological and histopathological variables. Can. J. Vet. Res. 52:239-248.

Poulsen K.P. \& McGuirk S.M. 2009. Respiratory Disease of the Bovine Neonate. Vet. Clin. North Am., Food. Anim. 25:121-137.

Sampaio I.B.M. 1998. Estatística Aplicada à Experimentação Animal. Fundação de Ensino e Pesquisa em Medicina Veterinária e Zootecnia, UFMG, Belo Horizonte. 221p.

Taylor J.A. 2000. Leukocyte responses in ruminants, p.391-404. In: Feldman B., Zinkl J. \& Jain N.C. (Eds), Schalm's Veterinary Hematology. $5^{\text {th }}$ ed. Lippincott Williams and Wilkins, Philadelphia.

Vogel G., Nicolet J., Martig J., Tschudi P. \& Meylan M. 2001. Pneumonia in calves: Characterization of the bacterial spectrum and the resistance patterns to antimicrobial drugs. Schweiz. Arch. Tierheilkd. 143(7):341-50. 